\title{
COLEÇÕES ZOOLÓGICAS DIDÁTICAS: UMA FERRAMENTA PARA A CONSERVAÇÃO DA BIODIVERSIDADE COSTEIRA
}

\author{
Marcio Camargo Araujo João ${ }^{1}$ \\ Helton Souza de Sá ${ }^{2}$ \\ Graziela Alexandre Souza ${ }^{3}$ \\ Otto Bismarck Fazzano Gadig ${ }^{4}$ \\ Marcelo Antonio Amaro Pinheiro ${ }^{5}$ \\ Ana Carolina Biscalquini Talamoni 6
}

Resumo: As Coleções Zoológicas Didáticas (CZD), quando contextualizadas, podem potencializar o ensino de zoologia e auxiliar os processos relativos à preservação e conservação das espécies. Este estudo relata uma experiência de Projeto de Ensino que, visando contribuir para ações de Educação Ambiental e o ensino e aprendizagem de zoologia, criou e implementou uma CZD em Escola Técnica do Município de São Vicente (SP). O material reuniu 30 espécies representativas da biodiversidade costeira do Litoral Centro de São Paulo, com potencial interdicisplinaridade a ser trabalhada nas aulas de ciências e biologia. Para implementar a CZD, foi oferecido um curso aos docentes da escola, além de material de apoio ao uso dessa coleção.

Palavras-chave: Baixada Santista; Biodiversidade Marinha; Educação Ambiental Emancipatória; Ensino de Zoologia.

\footnotetext{
${ }^{1}$ Universidade Estadual Paulista, Instituto de Biociências, Campus de Rio Claro. E-mail: marcio.joao@unesp.br, Link para o Lattes: http://lattes.cnpq.br/8305063283500801 'Universidade Estadual Paulista, Faculdade de Ciências, Bauru.

E-mail: tom_m.a13@hotmail.com. Link para o Lattes: http://lattes.cnpq.br/1945164810388435

3Universidade Estadual Paulista, Instituto de Biociências, Campus do Litoral Paulista.

E-mail: ella.unesp@gmail.com. Link para o Lattes: http://lattes.cnpq.br/1665531829352738

${ }^{4}$ Universidade Estadual Paulista, Instituto de Biociências, Campus do Litoral Paulista.

E-mail: otto.gadig@unesp.br. Link para Lattes: http://lattes.cnpq.br/2161551575581523

5 Universidade Estadual Paulista, Instituto de Biociências, Campus do Litoral Paulista.

E-mail: marcelo.pinheiro@unesp.br. Link para Lattes: http://lattes.cnpq.br/6829111589524333

6Universidade Estadual Paulista, Instituto de Biociências, Campus do Litoral Paulista.

E-mail: ana.talamoni@unesp.br. Link para Lattes: http://lattes.cnpq.br/4487235425259358
} 
Abstract: The Didactic Zoological Collections (DZC), when observed on a context, may strengthen the zoology teaching and contribute to the processes related to the species preservation and conservation. This study reports a teaching project experience aiming to contribute to environmental education actions and the teaching and learning in zoology, through a DZC built and implemented at a technical school of the São Vicente (São Paulo). This material brought together 30 representative species from central São Paulo coastal biodiversity, exploring interdisciplinary approaches to be studied in sciences and biology classes. To implement the DZC, a course was offered to the teachers, as well as a supplementary material to support the physical collection.

Keywords: Baixada Santista; Marine Biodiversity; Autonomous Environmental Education; Zoology Teaching.

\section{Introdução}

Estimativas apontam que nosso conhecimento sobre a biodiversidade global é ínfimo, compreendendo apenas 14\% (8,7 milhões) das espécies que vivem em nosso planeta (MORA et al., 2011). No caso dos oceanos, esse conhecimento é ainda menor, se restringindo a apenas $9 \%$ (2,2 milhões) das espécies viventes. Dentre esta imensa diversidade, muitos organismos já foram extintos antes mesmo de serem conhecidos (ZAHER; YOUNG, 2003). O conhecimento sobre a biodiversidade teve início com as expedições europeias, inauguradas pelas grandes navegações dos Séculos XVI e XVII (RAFFAINI, 1993), onde os materiais coletados compõem, até hoje, as primeiras coleções zoológicas do mundo como, por exemplo, a do Museu de História Natural de Paris (REBELO et al., 2020). Até 2010, estimava-se que estas "bibliotecas" já armazenavam mais de 3 bilhões de espécies vegetais e animais nas mais diversas coleções ao redor do mundo (PYKE; EHRICH, 2010).

As Coleções Zoológicas são compostas por conjuntos de espécimes inteiros ou partes deles, representando amostras de populações naturais (PAPAVERO, 1994). Estas apresentam grande potencial interdisciplinar, podendo interagir com questões históricas, culturais e, principalmente, de cunho científico (MOYA, 1998). Acessando as espécies ali depositadas, é possível aprimorar o entendimento sobre os ambientes em que elas vivem e, inclusive, perceber possíveis modificações naturais ou antrópicas de um mesmo local ao longo do tempo (SUAREZ; TSUTSUI, 2004). Assim, as coleções zoológicas atuam como uma biblioteca das espécies do passado e do presente, auxiliando na conservação da biodiversidade, por meio de pesquisas e do processo educacional (CANHOS et al., 2006), podendo ser utilizadas com cunho didático, sendo as Coleções Zoológicas Didáticas, aquelas que utilizam espécimes animais para o Ensino de Zoologia. O uso deste material no ambiente escolar tem sido visto como importante ferramenta educacional (MAGALHÃES et al., 2001), permitindo aos alunos que se aproximem efetivamente do objeto em estudo (RESENDE et al., 2002). Apesar disso, 
Prigol e Gianott (2008) abordaram algumas dificuldades para realizar tais práticas, que estão relacionadas, principalmente, à falta de preparo dos docentes. Essa dificuldade é somada ao sucateamento das Instituições Públicas de Ensino que, dificilmente, apresentam condições físicas e materiais para compor e manter estas coleções (ZANELLA et al., 2008) ou condição financeira para que os alunos possam visitar instituições com melhor situação para o uso dessas coleções (SULZBACH; JOHANN, 2021). Em contraponto a tais dificuldades, muitas escolas já trabalham com animais fixados durante as aulas de ciências e biologia (MARANDINO et al., 2014).

Segundo estudos já realizados, o uso de espécimes animais ou vegetais em aulas práticas pode potencializar a assimilação do conteúdo em até $75 \%$ (MAGALHÃES et al., 2001; SANTOS; SOUTO, 2011). MARANDINO et al. (2014) ressaltaram que o contato dos alunos com este material é bastante impactante, oportunizando a melhor assimilação da informação teórica recebida. Tal condição estimula os educandos a saírem da rotina de uma aula tradicional, permitindo uma perspectiva de ensino contextualizada, problematizadora e investigativa (MUNFORD; CAIXETA, 2007). Ao estarem em contato com estes objetos demonstrativos, diversas habilidades cognitivas podem ser desenvolvidas, o que permite trabalhar o raciocínio científico durante as aulas (HAYDT, 2012). Por fim, este processo de ensino e aprendizagem se torna mais significativo quando são utilizadas espécies de conhecimento comum aos alunos (LIMA et al., 2011), admitindo o enfrentamento de problemas de cunho socioambiental, presentes em seu diaa-dia (IZQUIERDO et al., 1999).

Uma abordagem contextualizada e aderente à realidade do aluno é necessária à melhor compreensão de problemas ambientais verificados atualmente, possibilitando que desenvolvam uma "consciência ecológica" (PINHEIRO et al., 2017). Esta temática se faz cada vez mais urgente, principalmente pela diminuição drástica da biodiversidade verificada em todo 0 mundo (MILLENIUM ECOSYSTEM ASSESSMENT, 2005). A biodiversidade marinha é assunto de atenção pública, particularmente por seu comprometimento em virtude do elevado adensamento populacional humano em áreas costeiras, onde os ecossistemas têm sido sistematicamente impactados ou mesmo suprimidos (DUKE et al., 2007). No Brasil, destaca-se a Região Metropolitana da Baixada Santista (RMBS), Litoral Centro do Estado de São Paulo, que compreende 1,8 milhões de habitantes, distribuídos em seus nove municípios (CUNHA; FARIA, 2017), que abrigam diversos ecossistemas, (p. ex., estuários, manguezais, costões rochosos, dunas etc.), que apresentam expressiva diversidade animal (PINHEIRO et al., 2008). Nessa região vemos 0 histórico mais antigo de colonização do país, onde os ambientes locais convivem diariamente com diversos estressores de várias origens e magnitudes (PINHEIRO et al. 2010). Dentre eles, temos as atividades do Porto de Santos (o maior complexo portuário da América Latina) e do Polo Industrial de Cubatão (ZÜNDT et al., 2006), além do grande adensamento de moradias irregulares ocupando áreas de manguezal e efluentes não tratados que têm 
sido descartados in natura nos estuários (ABESSA; AMBROZEVICIUS, 2008). Tais impactos sobre a biodiversidade na região têm sido expressivos, que somados às atividades extrativistas de média e grande escala, têm trazido declínio populacional para muitas espécies (ARAÚJO et al., 2013).

$O$ processo educacional assume posição estratégica ao trabalhar com conceitos que permitam a compreensão de diversos aspectos da biologia de espécies representativas dos ecossistemas costeiros, sensibilizando os alunos para questões conservacionistas e, portanto, contribuindo para o debate sobre a necessidade de minimizar os diversos impactos ecossistêmicos (PINHEIRO et al., 2017). Assim, a partir da problematização, contribui o desenvolvimento da consciência crítica, ao relacionar as ameaças à biodiversidade com as relações de exploração estabelecidas pelo homem sobre a natureza, dentro de uma lógica neoliberal (LOUREIRO, 2005). Trabalhar com coleções zoológicas didáticas é uma estratégia importante para possibilitar discussões sobre a conservação dos animais (AZEVEDO et al., 2012), principalmente quanto a sua contextualização (MARICATO et al., 2007; PINHEIRO et al., 2020). O uso de espécies do cotidiano faz com que o educando se sinta parte do processo. Numa perspectiva de Educação Ambiental crítica, a possibilidade do aluno se relacionar ao meio, desenvolvendo sentimentos de pertencimento e responsabilidade socioambiental, pode direcioná-lo a mudança de atitudes e valores (LIMA, 2002).

Com base no exposto, o objetivo do presente trabalho foi relatar a experiência de um Projeto de Ensino de Ciências e Biologia, realizado em uma Escola Técnica do Município de São Vicente (Litoral Centro - SP), acerca da criação e uso de Coleções Zoológicas Didáticas (CZDs). Para isso, a CZD foi criada implementada junto à escola, por meio de um curso de formação continuada e respectivo material de apoio.

\section{Metodologia}

O trabalho foi desenvolvido em três etapas, a saber: 1) caracterização do local de estudo; 2) concepção e construção de uma CZD; e 3) implementação e doação da coleção à escola, acompanhada de um curso de formação continuada aos docentes e preparo de material suplementar de apoio.

\section{Caracterização do Local de Estudo}

O local escolhido para o desenvolvimento do projeto foi uma Escola Técnica (ETEC) no Município de São Vicente, São Paulo, Brasil. As atividades descritas foram conduzidas no contexto de um Projeto de Ensino denominado "O uso de Coleções Zoológicas Didáticas em Escolas Públicas, como ferramenta para o conhecimento e preservação da Biodiversidade Marinha e Costeira da Região Metropolitana da Baixada Santista". 
A instituição está localizada na região central do Município de São Vicente, dentro da macrorregião que detêm os maiores índices de habitabilidade, rendimento e escolaridade (PERES-COSTA et al., 2018). Apesar disto, os educandos da escola são oriundos de diversas outras regiões da cidade, ou até mesmo de outros municípios, não necessariamente participando da mesma classificação de rendimento descrita para o local da instituição. A escola oferta ensino técnico e médio, sendo que este último atende cerca de 210 alunos, compreendendo duas turmas por ano. As atividades escolares iniciaram em 2008 e diversos espaços se encontram ainda em implementação, como é o caso do laboratório de ciências.

\section{Concepção e Construção da Coleção Zoológica Didática (CZD)}

A concepção e construção do acervo teve como critério a contextualização da conservação da biodiversidade marinha e costeira da Região Metropolitana da Baixada Santista. Para a elaboração da coleção foram realizados contatos com grupos de pesquisa do Instituto de Biociências da UNESP - Campus do Litoral Paulista (UNESP IB/CLP), devotados aos animais costeiros e marinhos, assim como comunidades de pescadores, visando obter, por doação, espécimes de vários grupos taxonômicos que são comuns na Região Costeira da Baixada Santista. Desse modo, foram utilizados espécimes oriundos de pesquisas em andamento ou pela atividade de pesca regional, com nenhum deles sacrificado com a finalidade de compor a coleção. Parte do material doado das pesquisas já veio devidamente fixado pelos laboratórios dos doadores. Outros espécimes de mesma procedência, ou doados por pescadores, foram entregues frescos ou congelados, exigindo todo 0 procedimento metodológico para a sua correta fixação e conservação, seja em via úmida ou seca. Essa etapa do projeto foi a mais complexa, considerando desde a aquisição dos animais até sua fixação. Para algumas espécies houve a doação de mais de um exemplar (geralmente um casal), enquanto outras estiveram representadas por um único indivíduo.

A identificação dos animais foi feita até o nível de espécie, exceto para uma estrela-do-mar que teve a classificação ao nível de gênero. Esse procedimento foi efetuado com a ajuda de especialistas dos mesmos laboratórios, outros especialistas do IB/CLP, bem como por consulta de literatura científica pertinente. Para os invertebrados, a bibliografia utilizada compreendeu as publicações de Melo (1996 e 1999), Amaral et al. (2006) e Rios (2009). Para os vertebrados foram usados os estudos de Figueiredo e Menezes (1978, 1980 e 1985), Menezes e Figueiredo (1980 e 1985) e Gomes et al. (2010).

O acervo foi composto por espécimes de invertebrados e vertebrados, buscando contemplar os grupos inseridos no currículo dos alunos do ensino médio (BRASIL, 1999). Como parte da coleção, os espécimes em "via úmida" passaram por um processo prévio de fixação em formaldeído (formol) 10\% e/ou 
álcool etílico $70 \%$, de acordo com suas características morfofisiológicas (MARTINS, 1994) e, em seguida, acondicionados em frascos de vidro, onde foram conservados em álcool etílico $70 \%$. Para a conservação foi evitado o uso do formaldeído, por ser um produto tóxico e carcinogênico, bem como por promover a degradação do exoesqueleto calcário (p. ex., crustáceos, equinodermos etc.). Outros espécimes foram conservados em "via seca", sendo previamente fixados com formaldeído e, posteriormente, mantidos fora de frascos, em local sem incidência direta de luz solar e ventilado, para não ocorrerem danos a suas características morfológicas diagnósticas.

As Coleções Didáticas não requerem que o material seja identificado (nome científico binomial, ou seja, nível de espécie), como é usual nas Coleções Científicas (PAPAVERO, 1994), porém, em ambos os casos, a identificação por etiquetas é obrigatória. Sendo assim, em cada frasco foi acondicionado uma única espécie (com um ou mais espécimes) e inserida diretamente no líquido conservador uma etiqueta em papel vegetal, onde foram feitas anotações de dados essenciais a cada animal, relacionados às categorias taxonômicas de interesse (p. ex., Filo, Subfilo, Classe e Espécie), além do nome popular e informações sobre a coleta (p. ex., município/estado, ambiente, meio de coleta, nome dos coletores etc.).

\section{Implementação e Doação da CZD para a escola, Curso de Formação Continuada e Preparo de Material Suplementar de Apoio}

O processo de implementação da CZD, após sua doação à escola, foi acompanhado da realização de um curso de formação continuada aos professores de biologia da instituição, compreendendo uma aula expositivadialogada, com embasamento teórico para capacitação dos professores no uso e manutenção mais adequados dessa coleção. A aula foi ministrada no laboratório de ciências da unidade, utilizando equipamentos audiovisuais cedidos pela própria instituição.

Juntamente com o curso, a escola recebeu um material didático suplementar de apoio, sob forma de apostila, sendo sugerido que estivesse sempre anexa à coleção, já que seu conteúdo é vinculado à coleção doada, e constituído por fichas sumárias de cada espécie, seguindo a mesma ordem numérica apresentada nas etiquetas de cada material. Nas fichas constaram informações taxonômicas de cada espécie (Filo, Classe, Ordem e Espécie), bem como o nome popular, fotos, suas características morfoecológicas e, por fim, observações e curiosidades específicas. 


\section{Resultados e Discussões}

\section{Concepção e Construção da Coleção Zoológica Didática (CZD)}

A Coleção Zoológica Didática compreendeu animais representativos da Biodiversidade Aquática Marinha da Região Metropolitana da Baixada Santista. Os organismos que a compuseram apresentam papel de destaque nos ecossistemas da região, seja tanto ecológica, quanto socialmente, sendo costumeiramente observados pelos moradores locais em seu dia a dia, tanto em praias e costões rochosos, quanto em peixarias, aquário público etc.

O laboratório de ciências da escola, por estar, na ocasião, em fase de implementação, ainda não apresentava prateleiras, de modo que a coleção foi acomodada em uma das bancadas do local (Figura 1).

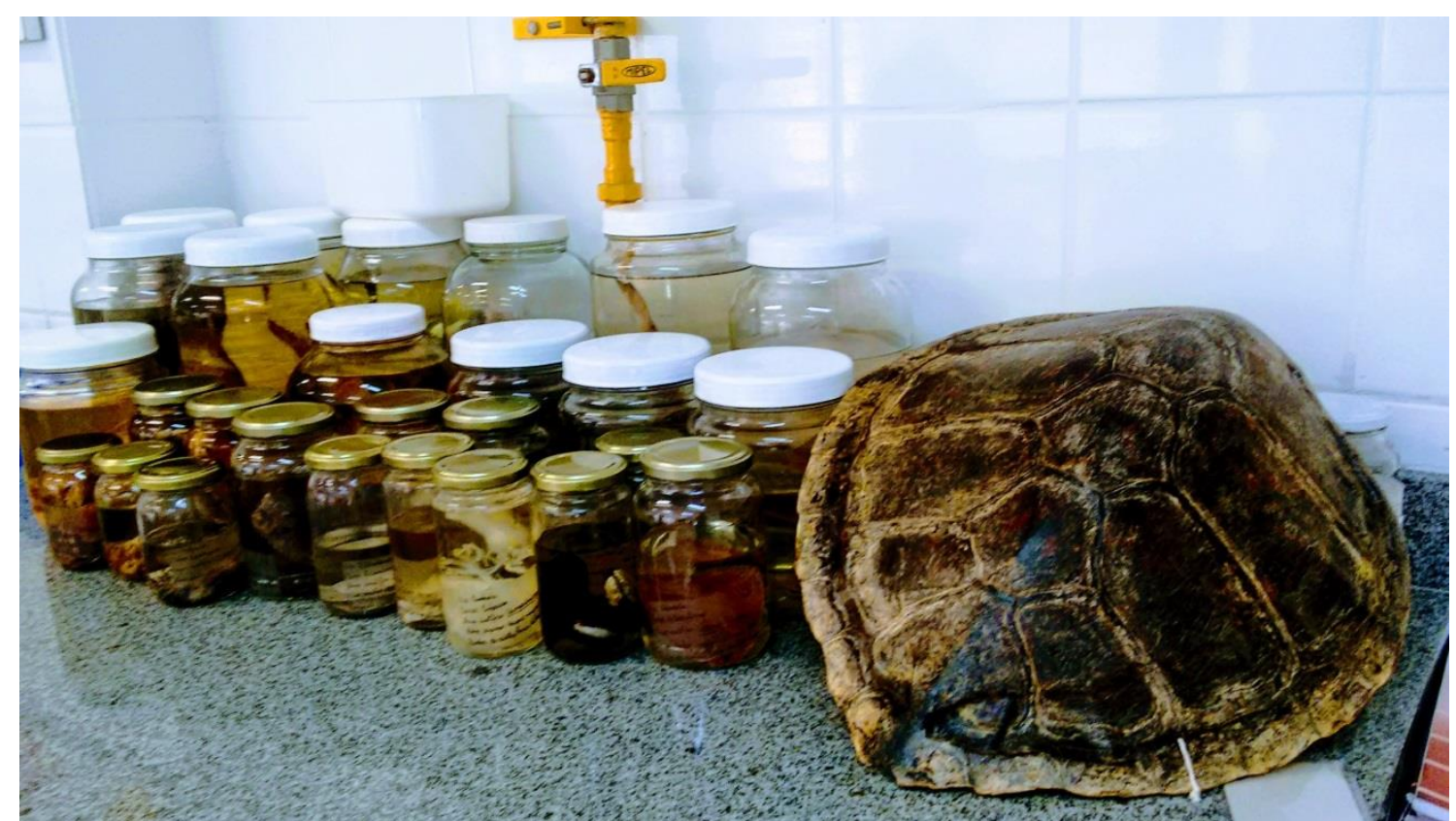

Figura 1: Coleção Zoológica Didática (CZD) doada a uma Escola Técnica de São Vicente (SP, Brasil), alocada no laboratório de ciências da unidade. Fonte: autores.

O acervo foi composto por 30 espécies de organismos costeiros e marinhos. A lista dos animais do acervo consta das Tabelas 1 e 2, compreendendo 17 espécies de invertebrados e 13 de vertebrados.

Os invertebrados foram todos conservados em "via úmida" e pertenciam aos seguintes grupos taxonômicos ( $\mathrm{n}=$ número de espécies): Filo Cnidaria $(n=2)$, Filo Mollusca $(n=4)$, Subfilo Crustacea $(n=7)$ e Filo Echinodermata $(n=4)$. Alguns deles apresentam particularidades, como o "polvo-comum" (Octopus vulgaris), que teve de ser submetido a uma adaptação feita com uso de placa de isopor, a fim de evitar que o animal afundasse no frasco, o que dificultaria sua observação. Para isso, foi costurada uma linha no isopor e na cabeça do animal, fazendo com que sua postura ficasse mais ereta e, assim, pudessem 
ser expostos mais claramente sua cabeça e braços com ventosas. As espécies do Subfilo Crustacea foram dispostas em fracos com um casal (macho e fêmea). Dentro dos invertebrados marinhos, o único grupo não contemplado na coleção, mas previsto no conteúdo ministrado para o ensino médio foi o Filo Porifera, popularmente conhecidos como "esponjas-do-mar" (embora existam espécies de água doce). O insucesso na obtenção de exemplares desse grupo se deu pela dificuldade de coleta e também por não terem sido estabelecidos contatos com grupos de pesquisa locais que trabalhassem com esses animais.

Tabela 1: Lista das espécies de invertebrados que compuseram a Coleção Zoológica Didática (CZD) de uma escola técnica do Município de São Vicente (SP), Brasil.

\begin{tabular}{ccc}
\hline Filo & Nome científico & Nome popular \\
\hline Cnidaria & Lychnorhiza lucerna & Água-viva \\
& Chiropsalmus quadrumanus & Vespa-do-mar \\
Stramonita brasiliensis & Búzios ou Saquaritá \\
Mollusca & Perna perna & Marisco \\
& Lolliguncula brevis & Lula \\
& Octopus vulgaris & Polvo comum \\
Arthropoda & Arenaeus cribarius & Siri-chita \\
Callinectes danae & Siri-azul \\
& Hepatus pudibundus & Caranguejo-baú \\
& Ucides cordatus & Caranguejo-uçá \\
& Farfantepenaeus paulensis & Camarão-rosa \\
& Clibanarius vittatus & Caranguejo-ermitão \\
& Callichirus major & Camarão-corrupto \\
& Mellita quinquiesperforata & Bolacha-da-praia \\
& Echinometra lucunter & Ouriço-do-mar \\
& Holothuria grisea & Pepino-do-mar \\
& Astropecten sp. & Estrela-do-mar \\
\hline
\end{tabular}

No caso dos vertebrados, foram colecionados animais do Filo Chordata (único grupo taxonômico que engloba os animais vertebrados), representados pelas seguintes classes: Classe Chondrichthyes, que trata dos peixes cartilaginosos $(n=3)$; Classe Actinopterygii, que agrupa os peixes ósseos $(n=9)$; e Classe Chelonii, relativa às tartarugas $(n=1)$. Desses, onze foram conservados em "via úmida" e dois em "via seca" (Tabela 2). Os materiais em 
"via seca" são partes das espécies em questão (p. ex., arcada dentária de tubarão e casco de tartaruga marinha) e tiveram suas etiquetas plastificadas e amarradas para não se perderem da peça e, consequentemente, comprometer a correta identificação. O casco da "tartaruga-verde" (Chelonia mydas) necessitou de um trabalho diferenciado, com maior tempo de exposição ao sol e boa circulação de ar, com posterior fixação em formaldeído $10 \%$, nova secagem e finalização com duas demãos de verniz para evitar a decomposição. Dentre os vertebrados, um grupo previsto no conteúdo da aula ministrada, mas não obtido para a coleção foi a Classe Mammalia. Isso ocorreu por dificuldade natural na obtenção de espécimes ou parte deles junto a grupos de pesquisa nessa temática e, principalmente, pela pesca, em função das rigorosas restrições legais sobre captura (PARENTE et al., 2017).

Tabela 2: Lista das espécies de vertebrados que compuseram a coleção zoológica didática de uma escola técnica de São Vicente, Brasil.

\begin{tabular}{ccc}
\hline Filo/Classe & Nome científico & Nome popular \\
\hline $\begin{array}{c}\text { Chordata/ } \\
\text { Chondrichthyes }\end{array}$ & Carcharhinus limbatus & Cação-frango \\
& Pseudobatos percellens & Cação-galha-preta* \\
& Genidens genidens & Raia-viola \\
Chilomycterus spinosos & Bagre-urutu \\
Achirus lineatus & Mugil curema & Baiacu-de-espinho \\
& Micropogonias furnieri & Linguado-de-água-doce \\
& Acanthistius brasilianus & Parati \\
& Ctenosciaena gracilicirrhus & Corvina \\
& Umbrina coroides & Pescada-do-norte ou \\
& Paralonchurus brasiliensis & Castanha
\end{tabular}

*arcada dentária; ${ }^{* *}$ casco.

O relato dos professores sobre a dificuldade de trabalhar com o conteúdo zoológico de forma contextualizada, determinou que a coleção fosse montada como procedimento auxiliar a este processo. As espécies escolhidas 
durante o projeto apresentam forte potencial de contextualização durante as aulas práticas, por constarem entre as mais comuns na região em várias circunstâncias. Trabalhar com o conteúdo dentro de uma perspectiva ecológica, quando contextualizada ao ambiente e cotidiano do aluno, faz com que ele se sinta integrante do processo, desenvolva sentimentos de pertencimento e responsabilidade socioambiental. Isso também resulta na Educação Ambiental emancipatória, que permite ao educando perceber a forma como se relaciona às outras espécies, caminhando para uma transformação de valores e práticas (LIMA, 2002; LOUREIRO, 2005). Nessa ótica, temos alguns aspectos problematizadores que podem ser trabalhados pelos professores junto à coleção cedida. Dentre eles, algumas espécies do acervo doado estão listadas como ameaçadas de extinção por atividades humanas (p. ex., descarte de lixo e pesca - ICMBIO, 2016). Outra questão são as espécies "estigmatizadas" pela população, como os tubarões, que têm sempre sido considerados perigosos, sem destaque ao papel fundamental que exercem no ecossistema marinho. A maioria das espécies de crustáceos e peixes é encontrada em peixarias, sendo popularmente conhecidos como "frutos-do-mar" e comercializados com frequência na região, tais como o camarão-rosa, que tem sua captura vinculada à pesca comercial de arrasto (DIAS-NETO, 2011). Detalhamentos de algumas das formas de contextualização foram incluídos no próximo tópico do presente trabalho, sendo abordados junto aos docentes durante o curso de formação.

Aproximando os educandos do conteúdo, o docente pode criar diversos questionamentos sobre a forma como cada indivíduo interage com o meio em que vive. Esta aproximação faz com que a atividade supere uma simples comparação morfológica e consiga abordar cada espécie de forma interdisciplinar (SILVA et al., 2014). Desta forma, LIZAMA et al. (2021) destacam a importância do educando se conectar de forma verdadeira com o conteúdo, atuando de forma crítica na construção do conhecimento e possibilitando a preservação do meio ambiente a partir de uma abordagem interdisciplinar.

\section{Implementação e Doação da CZD para a escola, Curso de Formação Continuada e Preparo de Material Suplementar de Apoio}

Prigol e Gianott (2008) destacam que os docentes se sentem despreparados para trabalhar com alguns conteúdos de forma alternativa, como é o caso de aulas práticas. Nesse sentido, durante o presente projeto foram realizadas duas ações para auxiliar os professores no uso da Coleção Zoológica Didática: 1) curso de formação continuada para os professores de biologia da escola e 2) a elaboração e disponibilização de uma apostila como material suplementar de apoio ao uso da coleção. Durante o curso foi possível a troca de experiências dos integrantes do projeto e os dois professores de biologia da escola. Vale ressaltar que ambos, de antemão, afirmaram que suas aulas de zoologia tangem apenas descrições e diferenciações morfológicas dos 
animais, existindo como grande dificuldade a integração deste conteúdo ao cotidiano dos alunos. A princípio, isto cumpre com as diretrizes encontradas no material de apoio utilizado na Rede Estadual de Ensino, que define se esperar dos alunos a capacidade de identificar e classificar os animais durante o Ensino de Zoologia (SÃO PAULO, 2014). Contudo, contradiz o previsto pela Base Nacional Comum Curricular (BNCC) do ensino médio (BRASIL, 2018, p. 539) para o eixo das Ciências e Tecnologias, esperando do aluno “... propor ações individuais e coletivas que aperfeiçoem processos produtivos, minimizem impactos socioambientais e melhorem as condições de vida em âmbito local, regional e/ou global". A partir do momento que essa diretriz não especifica disciplinas dentro do eixo, entende-se que todos os conteúdos precisam estimular esse aperfeiçoamento. Muitas vezes esta dualidade entre normativas e materiais de apoio, muitas vezes, desestimula o docente. Afinal, vale ressaltar que grande parte dos materiais didáticos abordam exemplos e problemas distantes do cotidiano dos participantes do processo de ensino e aprendizagem. Perogaro e Sorretino (2002), por exemplo, avaliaram que o mamífero marsupial mais comum em livros didáticos é o canguru, que é uma espécie natural da Austrália, ignorando o popular "gambá", que é uma espécie de marsupial nativa da Mata Atlântica Brasileira. Um ensino descontextualizado, de fato, desestimula as mudanças sociais e a aproximação entre a ciência e a sociedade (CACHAPUZ et al., 2005). Contudo, isso ocorre não somente com os alunos da educação básica, mas com os docentes formados nesta mesma perspectiva. De certa forma, isso legitima os conteúdos utilizados no preparo do curso de capacitação e do material de apoio, compostos por três blocos de conteúdo sobre a RMBS, como se segue: 1) Biodiversidade Marinha e Costeira; 2) Ecossistemas Marinhos e Costeiros; e 3) Grupos Animais Representativos.

Os dois primeiros blocos são fortemente interligados, descrevendo os principais ecossistemas da RMBS (p. ex., costões rochosos, praias arenosas, estuários e manguezais), dos quais os animais da coleção criada são integrantes. Pinheiro et al. (2008) discutem os principais aspectos envolvidos na dinâmica de cada um destes ecossistemas, de forma que ele foi utilizado para a construção das sessões do curso e da apostila. Vale ressaltar que estes ecossistemas agregam aspectos positivos à economia da região, por meio de atividades vinculadas ao turismo, à pesca e, de forma especial, com o Porto de Santos (ZÜNDT, 2006). Esses fatores, entretanto, carregam consigo intensos impactos diretos sobre a biodiversidade, já que a região possui um dos mais antigos históricos de colonização do país e uma crescente supressão dos ambientes naturais (PINHEIRO et al., 2010). Duarte et al. (2016) sintetizam as fontes de impacto de algumas cidades do litoral Centro e Sul de São Paulo, sendo São Vicente a cidade mais populosa utilizada no estudo e, consequentemente, aquela de maior impacto antrópico. Mediante esses problemas, é crucial que o ensino de zoologia das escolas da RMBS, em especial na instituição que recebeu a coleção, seja conduzido de forma interdisciplinar, tomando por base o contexto socioambiental de degradação 
ambiental. Silva et al. (2014) argumentaram a importância dessa mudança de direção na formação dos alunos como cidadãos, aproximando os educandos às práticas de pesquisa por meio da alfabetização científica. Nesse sentido, a CZD pode contribuir para o desenvolvimento de habilidades cognitivas inerentes à prática científica, tais como a capacidade de observação, descrição, classificação e conceituação.

Já o terceiro bloco, relativo aos animais representativos da região de estudo, foi o mais extenso, pois ali foram abordados os animais que compuseram a coleção, com suas fotos e principais características biológicas e diagnósticas para identificação. Nessa parte, foram incluídas as fichas sumarizadas de cada espécie, buscando facilitar a identificação dos animais do acervo e apresentá-lo de forma acessível ao docente. De forma paralela, o último item de cada ficha, denominado "observações", agregou informações que vinculam o cotidiano dos habitantes da região com cada espécie. Isso ocorre, por exemplo, em espécies de pescado que servem de alimento e, corriqueiramente, são vistas em mercados e feiras de frutos-do-mar, como é o caso da corvina (Micropogonias furnieri) e do caranguejo-uçá (Ucides cordatus), este último comercializado até mesmo em rodovias da região. Em outra vertente, foram incluídas espécies com elevado grau de ameaça de extinção, registradas na última Lista Vermelha do Brasil (ICMBIO, 2016), como a raia-viola (Pseudobatos percellens) e o cação-galha-preta (Carcharhinus limbatus), ambos ameaçados pela intensa atividade pesqueira, mas encontrados em mercados onde são comercializados com seu nome popular "cação" (BERNARDO et al., 2020). Durante o curso com os professores, esse momento foi conduzido junto aos animais da coleção, sendo o primeiro contato dos docentes com a CZD e gerando discussões de aspectos que permitem a contextualização envolvendo cada espécie utilizada. O curso e a apostila buscaram seguir o descrito por Danaga (2004), apresentando aos docentes mais do que a teoria, mas um estímulo à sua criatividade durante o uso da coleção.

Por fim, os docentes receberam treinamento sobre como realizar a manutenção da coleção doada, de modo que a escola não dependa dos participantes do projeto em situações futuras. Todo esse processo capacitou e conferiu autonomia aos docentes durante as suas disciplinas, para terem a base necessária para trabalhar com os animais cedidos. Os professores foram muito participativos ao longo do curso e se mostraram bastante satisfeitos com o produto final entregue. Destacaram, também, que já haviam trabalhado com Coleções Zoológicas Didáticas ao longo de suas carreiras nas escolas, porém não o fazem mais frequentemente em função da falta de material ou verba para construir e manter uma coleção na escola. De modo geral este fato confirma que os docentes iniciam suas carreiras com estímulo à busca de métodos alternativos, embora o sucateamento das instituições públicas de ensino dificulte e desencoraje suas atuações neste sentido (PASQUALI et al., 2006; ZANELLA et al., 2008). 


\section{Conclusões}

Os docentes concordam com o grande potencial do uso de coleções didáticas no Ensino de Zoologia, contudo, a falta de estrutura e incentivo os desmotiva. A criação de coleções em instituições de ensino público pode ser viabilizada por instituições de ensino superior, já que elas apresentam mais estrutura e verba para confeccionar materiais dessa natureza, o que não isenta o Poder Público dessa obrigação.

Materiais de auxílio às coleções cedidas nas escolas propiciam autonomia aos docentes e devem estar vinculados aos projetos futuros. Contudo, as escolas públicas encontram dificuldade na aquisição desses materiais didáticos. Projetos de ensino e pesquisa que vinculem universidades e escolas públicas podem se configurar como alternativa para auxiliar na mitigação desse problema, considerando que a universidade tem melhores condições técnicas e logísticas para confeccionar uma Coleção Zoológica.

O número de trabalhos sobre Coleções Zoológicas Didáticas abordando organismos marinhos e costeiros são incipientes em razão da grande extensão de costa brasileira. Esse instrumental possibilita conhecimentos transversais vinculando conservação, recursos pesqueiros, pressões antrópicas e a importância de se manter esse riquíssimo patrimônio natural para as futuras gerações. Portanto, em função do aumento demográfico humano em áreas costeiras e do expressivo impacto deletério sobre esses ecossistemas, as Coleções Zoológicas, desde que temáticas e contextualizadas, desempenham um papel potencial e promissor à emancipação dos alunos. Utilizando as coleções nesse contexto interdisciplinar, pode emancipar os educandos para atuarem na conservação da biodiversidade em escala local ou regional, transformando-os em agentes multiplicadores da percepção adquirida por novas tratativas e métodos de ensino.

É altamente recomendável que sejam elaborados trabalhos que avaliem a efetividade das Coleções Zoológicas junto aos alunos, bem como da proposição de atividades que possam estimular habilidades técnico-científicas vinculadas ao Ensino de Zoologia.

\section{Agradecimentos}

Os autores gostariam de agradecer todos os laboratórios de pesquisa do Instituto de Biociências da UNESP - Campus do Litoral Paulista (UNESP IB/CLP) e seus projetos de pesquisa, por cederem material para a confecção da referida Coleção Zoológica Didática. São eles: Laboratório de Conservação de Crustáceos e Ambientes Costeiros (CRUSTA), Laboratório de Biologia, Ecologia e Fisiologia de Organismos Aquáticos, Laboratório de Pesquisa de Elasmobrânquios (ELASMOBRASIL), Laboratório de Evolução e Diversidade Aquática (LEDA) e Museu Itinerante de Biologia Marinha (MIBIM). O primeiro autor gostaria de agradecer à Fundação de Amparo à Pesquisa do Estado de São Paulo (FAPESP) pela bolsa de mestrado (2019/16581-9). Os autores 
agradecem ao financiamento do projeto pela Pró-Reitoria de Graduação da UNESP (PROGRAD) e Programa de Núcleos de Ensino. Por fim, agradecer a todos os setores da escola técnica que recebeu o projeto, em especial aos professores de biologia que acompanharam todo o processo relatado no presente estudo.

\section{Referências}

ABESSA, D.M.S.; AMBROZEVICIUS, A.P. Aspectos sobre poluição aquática, tratamento e disposição de esgotos na zona costeira. In: Fontes, R.F.C., Oliveira, A.J.F.C., Pinheiro, M.A.A. (Eds.). Visão didática sobre o meio ambiente na Baixada Santista. São Vicente, Universidade Estadual Paulista: p. 75-94, 2008.

AMARAL, A.C.Z.; RIZZO, A.E.; ARRUDA, E.P. Manual de identificação dos invertebrados marinhos da Região Sudeste-Sul do Brasil, Volume 1. São Paulo: EdUSP, p. 288, 2006.

ARAUJO, G.S.; MOREIRA, L.B.; MORAIS, R.D.; DAVANSSO, M.B.; GARCIA, T.F.; CRUZ, A.C.F.; ABESSA, D.M.S. Ecotoxicological assessment of sedimentis from na urban marine protected area (Xixová-Japuí State Park, SP, Brazil). Marine Pollution Bulletin, v. 75, p. 62-68, outubro/2013.

AZEVEDO, H.J.C.C.; FIGUEIRÓ, R.; ALVES, D.R.; VIEIRA, V.; SENNA, A.R. O uso de coleções zoológicas como ferramenta didática no ensino superior: um relato de caso. Revista Práxis, Volta Redonda, v. 7, p. 43-48, janeiro/2012.

BRASIL. Parâmetros Curriculares Nacionais: Ensino Médio (PCNEM). Brasília: Ministério da Educação e Cultura, 2018.

BRASIL. Base Nacional Comum Curricular: ensino médio. Brasília: Ministério da Educação, 2018.

BEHRENS, M.A. O paradigma emergente e a prática pedagógica. Revista Brasileira de Estudos Pedagógicos, Brasília, v. 80, n. 196, p. 383-403, dezembro/1999.

BERNARDO, C.; ADACHI, C. L. A.; MAYUMI, A.; CRUZ, V. P.; FORESTI, F.; LOOSE, R. H.; BORNATOWSKI, H. The label -cação- is a shark or a ray and can be a threatened species! Elasmobranch trade in Southern Brazil unveiled by DNA barcoding. Marine Policy, v. 116, p. 103920-103927, junho/2020.

CACHAPUZ, A.; PÉREZ, D.G.; CARVALHO, A.M.; PRAIA, J.; VILCHES, A. A necessária renovação do ensino das ciências. São Paulo: Cortez, 2005, $246 p$.

CANHOS, D.A.L.; SOUZA, S.; CANHOS, V.P. Coleções biológicas e sistemas de informação. In: M.C.T. Diretrizes e estratégias para modernização de coleções biológicas brasileiras e a consolidação de sistemas integrados de informação sobre biodiversidade. Brasília: Ministério de Ciências e Tecnologia, p. 241-314, 2006. 
CUNHA, J. M. P.; FARIA, L. A. C. Região Metropolitana da Baixada Santista: diversidades socioespaciais na virada para o século XXI. Campinas: Librum Editora, p. 113, 2017.

DANAGA, N.H.P. Desenvolvimento de um programa educacional de formação continuada - o tornar-se educador a partir de reflexões (trans)formações e busca de melhoria do ensino e da aprendizagem. Dissertação (Mestrado) Faculdade de Educação - Universidade Federal de São Carlos (UFSCAR), São Carlos, 2004.

DIAS-NETO, J. (Org.) Proposta de Plano Nacional de Gestão para uso sustentável de camarões marinhos do Brasil. Brasília: Instituto Brasileiro do Meio Ambiente. p. 242, 2011.

DUKE, N.C.; MEYNECKE, J.O.; DITMANN, S.; ELLISON, A.M.; ANGER, K.; BERGER, U.; CANNICCI, S.; DIELE, K.; EWEL, K.C.; FIELD, C.D.; KOEDAM, N.; LEE, S.Y.; MARCHAND, C.; NORDHAUSS, I.; DAHDOUH-GUEBAS, F. A world without mangroves? Science, v. 317, p. 41-43, julho/2007.

DUARTE, L.F.A.; SOUZA, C.A.; NOBRE, C.R.; PEREIRA, C.D.S.; PINHEIRO, M.A.A. Multi-level biological responses in Ucides cordatus (Linnaeus, 1763) (Brachyura, Ucididae) as indicators of conservation status in mangrove areas from the western Atlantic. Ecotoxicology and Environmental Safety, v. 133, p. 176-187, julho/2016.

FIGUEIREDO, J. L.; MENEZES, N. A. Manual de peixes marinhos do Sudeste do Brasil. II. Teleostei (1). Museu de Zoologia, Universidade de São Paulo, p. 110, 1978.

FIGUEIREDO, J. L.; MENEZES, N. A. Manual de peixes marinhos do Sudeste do Brasil. III. Teleostei (2). Museu de Zoologia, Universidade de São Paulo, p. 90, 1980.

FIGUEIREDO, J. L.; MENEZES, N. A. Manual de peixes marinhos do Sudeste do Brasil. VI. Teleostei (5). Museu de Zoologia, Universidade de São Paulo, p. 116. 2000.

GOMES, U.L.; SIGNORI, C.N.; GADIG, O.B.F. SANTOS, H.S. Guia para identificação de tubarões e raias do Rio de Janeiro. Rio de Janeiro: Technical Books Editora, p. 234, 2010.

HAYDT, R.C.C. 2011. Curso de didática geral. São Paulo: Ática, 1999, 248p.

INSTITUTO CHICO MENDES DE CONSERVAÇÃO DA BIODIVERSIDADE (ICMBIO). Sumário Executivo: Livro Vermelho da Fauna Brasileira Ameaçada de Extinção. Brasília: Ministério do Meio Ambiente, 2016.

IZQUIERDO, M.; SANMARTÍ, N.; ESPINET, M. Fundamentación y diseño de lasprácticas escolares de ciências experimentales. Enseñanza de las Ciencias, Barcelona, v. 17, n. 1, 45-60, 1999. 
LIMA, G.F.C. Crise ambiental, educação e cidadania: os desafios da sustentabilidade emancipatória. In: LOUREIRO, C.F.B.; LAYRAGUES, P.P.; CASTRO, R.S. (Orgs.). Educação Ambiental: repensando o espaço da cidadania. São Paulo: Cortez, 2002.

LIZAMA, M.A.P.; ZAVASKI, F.; WACHHOLZ, L.A. Museu virtual: o ensino de zoologia e a Educação Ambiental sob um olhar diferente, antes e depois da COVID-19. Revista Brasileira de Educação Ambiental, v. 16, n. 1, p. 293304, 2021.

LOUREIRO, C.F.B. Complexidade e dialética: contribuições à práxis política e emancipatória em Educação Ambiental. Educação e Sociedade, Campinas, v. 26, n. 93, p. 1473-1494.

MAGALHÃES, C.; SANTOS, J.L.C.; SALEM, J.I. Automação de coleções biológicas e informações sobre a biodiversidade da Amazônia. Parcerias Estratégicas, Brasília, v. 12, p. 294-312, setembro/2001.

MAIA, L.L.; SILVA, J.F.; GARCIA, J.F.M. O uso de coleções zoológicas a partir da abordagem do ensino por investigação - Possibilidades de integração de conteúdos. Anais do VIII Encontro Nacional de Pesquisa em Educação em Ciências, 2011.

MARTINS, U.R. Coleção taxonômica. In: PAPAVERO, N. (Org.). Fundamentos práticos de taxonomia zoológica. São Paulo: Editora UNESP/FAPESP, p. 18-43, 1994.

MARANDINO, M.; RODRIGUES, J.; SOUZA, M.P.C.S. Coleções como estratégia didática para a formação de professores na pedagogia e na licenciatura de ciências biológicas. Anais do $\mathrm{V}$ Encontro Nacional dos Estudantes de Biologia, 2014.

MARICATO, H.S.; OLIVEIRA, W.D.; BORGES, M.F.; DINIZ, J.L.M. A utilização da prática em zoologia através de coleções didáticas: um recurso para a construção dos conhecimentos dos alunos do ensino médio do município de Jataí - Goiás. Anais do XXIII Congresso de Educação do Sudoeste Goiano, 2007.

MELO, G.A.S. Manual de identificação dos Brachyura (caranguejos e siris) do litoral brasileiro. 1. ed. São Paulo: Pleiade. v. 1. p. 603, 1996.

MELO, G.A.S. Manual de identificação dos Crustacea Decapoda do litoral brasileiro: Anomura, Thalassinidea, Palinuridea e Astacidea. 1. ed. São Paulo: Pleiade. v. 1, p. 556, 1999.

MENEZES, N. A.; FIGUEIREDO, J. L. Manual de peixes marinhos do Sudeste do Brasil. IV. Teleostei (3). Museu de Zoologia, Universidade de São Paulo. p. 96, 1980.

MENEZES, N. A.; FIGUEIREDO, J. L. Manual de peixes marinhos do Sudeste do Brasil. V. Teleostei (4). Museu de Zoologia, Universidade de São Paulo, p. 105. 1985. 
MILLENIUM ECOSYSTEM ASSESSMENT. Ecosystems and Human Wellbeing: Biodiversity Synthesis. Washington D.C.: Resources Institute, 2005.

MORA, C.; TITTENSOR, D.P.; ADL, S.; SIMPSON, A.G.B.; WORM, B. How many species are there on earth and in the ocean? PLOS Biology, v. 9, n. 8, p. 1-8, agosto/2011.

MOYA, M.C.H. Las coleciones enun Museu Interactivo. In: VALDÉZ, J.F. (Org.). Cómo Hacer um Museo de Ciencias. Cidade do México (MX): Ediciones Cientificas Universitarias, p. 59-67, 1998.

MUNFORD, D.; CAIXETA, M.E.C.L. Ensinar ciências por investigação: em que estamos de acordo? Ensaio Pesquisa em Educação em Ciências, Belo Horizonte, v. 9, n. 1, p. 89-111, junho/2007.

PAPAVERO, N. Fundamentos práticos da taxonomia zoológica: coleções, bibliografia e nomenclatura. São Paulo: Editora da Universidade Estadual Paulista (UNESP), 1994, 296p.

PARENTE, C.L.; ARAÚJO, J.P.; MONTEIRO-NETO, C.; REIS, E.C. Mamíferos marinhos no Brasil: aspectos gerais, ameaças, pesquisa e conservação. In: REIS, E.C.; CURBELO-FERNANDEZ, M.P. (Eds.). Mamíferos, quelônios e aves: caracterização ambiental regional da Bacia de Campos, Atlântico Sudoeste. Rio de Janeiro: Elsevier. Habitats, v. 7. p. 15-33, 2017.

PASQUALI, I.S.R.; MASSING, J.; CUNHA, J.T.; ABICHT, A.M. Educação Ambiental: material alternativo em auxílio à Educação Ambiental para aplicação de práticas no ensino médio de biologia. Anais do XIII SIMPEP, 2006.

PEROGARO, J.L.; SORRENTINO, M. A fauna nativa a partir de ilustrações dos livros didáticos - Ciências e Biologia. Anais do Encontro de Perspectivas do Ensino de Biologia, 2002.

PYKE, G.H.; EHRLICH, P.R. Biological collections and ecological environmental research: a review, some observations and a look to the future. Biological Reviews, v. 85, p. 247-266, abril/2010.

PINHEIRO, M.A.A.; OLIVEIRA, A.J.F.C.; FONTES, R.F.C. Introdução ao panorama ambiental da Baixada Santista. In: OLIVEIRA, A.J.F.C.; PINHEIRO, M.A.A.; FONTES, R.F.C. (Orgs.). Panorama Ambiental da Baixada Santista. São Vicente, Universidade Estadual Paulista (UNESP) - Campus do Litoral Paulista (CLP), p. 1-5, 2008.

PINHEIRO, M.A.A.; SANTOS, C.M.H.; WUNDERLICH, A.C.; MILÃO-SILVA, F.; PERES-COSTA, W.C. Educação Ambiental sobre manguezais na baixadasantista: uma experiência da UNESP/CLP. Revista Ciência em Extensão, São Paulo, v. 6, n. 1, p. 19-27, 2010.

PINHEIRO, M.S.; SCOPEL, J.M. BORDIN, J. Confecção de uma coleção didática para o ensino de zoologia: conhecer para preservar o Litoral Norte do Rio Grande do Sul. Scientia cum Industria, Santa Catarina, v. 5, n. 3, p. 156160 , dezembro/2017.

revista brasileira educação ambiental 
PINHEIRO, M.S.; SCOPEL, J.M. BORDIN, J. A importância de uma coleção didática de Zoologia para a sensibilização ambiental dos ecossistemas costeiros. Scientia cum indústria, Santa Catarina, v. 8 , n. 1, p. 7-11, janeiro/2020.

RAFFAINI, P.T. The contemporary museum and the cabinets of curiosities. Revista do Museu de Arqueologia e Etnologia, v.3, p. 159, 1993.

REBELO, D.; MOREIRA, D.O.; LOSS, A.C.; ROCHA, R.G. Mamíferos Brasileiros em Museus Portugueses: o reviver de expedições centenárias. Boletim da Sociedade Brasileira de Mastologia, v. 87, p. 1-10, março/2020.

RESENDE, A.L.; FERREIRA, J.R.; KLOSS, D.F.M.; NOGUEIRA, J.D.; ASSIS, J.B. Coleções de animais silvestres, fauna do cerrado do sudoeste goiano, 0 impacto em Educação Ambiental. Arquivos da Apadec, v.6, n.1, p. 35-41, 2002.

RIOS, E.C. Compendium of Brazilian seashells. Rio Grande: Editora Evangraf, p. 676, 2009.

ANTOS, D.C.; SOUTO, L.S. Coleção entomológica como ferramenta facilitadora para a aprendizagem de Ciências no ensino fundamental. Scientia Plena, v. 7, n. 5, p. 1-8, maio/2011.

SÃO PAULO (Estado). Caderno do Professor - Volume 1, Biologia: Ciências da Natureza - $3^{\text {a }}$ série do Ensino Médio. São Paulo, Secretaria da Educação do Estado de São Paulo, 2014.

SILVA, T.A.G.; CORRÊA, B.C.; MATOS, G.I. Desenvolvimento e organização de coleção zoológica didática no CEFET/RJ: desafios, possibilidades e primeiras aplicações. Revista da SBEnBIO, v. 7, p. 7151-7161, outubro/2014.

SUAREZ, A.V.; TSUTSUI, N.D. 2004. The value of museum collections for research and society. BioScience, Uberlândia, v. 54, n. 1, p. 66-74, 2004.

SULZBACH, A.; JOHANN, L. Avaliação do uso do Museu de Ciências UNIVATES como espaço não formal de ensino por professores de escolas públicas e particulares. Revista Brasileira de Educação Ambiental, v. 16, n. 1, p. 19-21, 2021.

ZAHER, H.; YOUNG, P.S. As coleções zoológicas brasileiras: panorama e desafios. Ciência e Cultura, Campinas, v. 55, n. 3, p. 24-26, setembro/2003.

ZANELLA, G.V.; NASCIMENTO, D.F.; FERRAZ, D.F.; JUSTINA, L.A.D.; PLANK, P.Y.; PEGORARO, T. Reestruturação do laboratório de um colégio de rede pública de Cascavel, Paraná, Brasil. Revista Brasileira de Biociências, Porto Alegre, v. 6, n. 1, p. 39-41, setembro/2008.

ZÜNDT, C. Baixada santista: uso, expansão e ocupação do solo, estruturação de rede urbana regional e metropolização. In: CUNHA, J.M.P. (Org.). Novas Metrópoles Paulistas: população, vulnerabilidade e segregação. Campinas: Núcleo de Estudos de Poluição/UNICAMP, p. 605-336, 2006. 